\title{
An effective and novel method for teaching applied facial anatomy and related procedural skills to esthetic physicians
}

This article was published in the following Dove Press journal: Advances in Medical Education and Practice

\author{
Narendra Kumar' \\ Eqram Rahman² \\ Philip J Adds ${ }^{2}$
}

'Postgraduate Medical Institute, Faculty of Medical Science, Anglia Ruskin University, Chelmsford, UK; ${ }^{2}$ Department of Anatomical Sciences, Institute of Medical and Biomedical Education, St. George's University of London, London, UK
Correspondence: Narendra Kumar Postgraduate Medical Institute, Faculty of Medical Science, Anglia Ruskin University, Bishop Lane, Chelmsford CMI ISQ, UK Tel +44 I 245684653

Email narendrakumar226@gmail.com
Background: An understanding of facial anatomy is crucial for the safe practice of nonsurgical facial esthetic procedures. Contextual learning, aided with instructional design, enhances the trainees' overall learning experience and retention, and makes a positive impact on the performance of procedural skills. The present study aimed to develop a teaching approach based on Bloom's taxonomy involving cognitive, affective, and psychomotor learning domains.

Materials and methods: The practicability of Assess \& Aware, Demonstrate, Decode, Act \& Accomplish, Perform, Teach \& Test (ADDAPT), a new approach to teaching applied facial anatomy and procedural skills to esthetic physicians in a large group setting, was evaluated in this study. Study participants were from two cohorts $(n=124)$ who underwent 2 days of applied anatomy training in Singapore. Pre- and post-course multiple choice questions and objective structured practical examination were conducted to measure the effectiveness and applicability of the teaching model. Expert raters, table demonstrators, and participants rated the steps involved in the ADDAPT model on an 11-point Likert scale.

Results: Pre- and post-course evaluation mean scores for multiple choice questions were 17.32 $(\mathrm{SD} \pm 3.36)$ and $22.61(\mathrm{SD} \pm 1.77)$ and for objective structured practical examination were 24.53 ( $\mathrm{SD} \pm 4.63)$ and 43.57 (SD \pm 5.35$)$, respectively $(P<0.001)$. Inter-rater agreement, expressed as the intraclass correlation coefficient, was 0.91 (95\% CI: 0.62-0.98) for expert raters and 0.90 (95\% CI: 0.78-0.97) for table demonstrators, which reflects the real strength of sound educational practice. The trainees well accepted the model and found the sessions intellectually stimulating. Trainees' feedback stated that the learning experience was enhanced by the repeated observation and constructive feedback provided by the tutors.

Conclusion: The ADDAPT model is practical to instruct a large group of trainees in clinical anatomy and procedural skill training. This approach to instructional design may be feasible and transferable to other areas of psychomotor skill training in medical education.

Keywords: facial anatomy, anatomy teaching model, anatomy knowledge, pre- and posttest, OSPE, Bloom's taxonomy, instructional design

\section{Introduction}

The recent availability of "volume" fillers has extended cosmetic physicians' ability to contour facial architecture nonsurgically and with minimal discomfort. The deeper plane injection can create pleasing facial shapes, shaped brows, youthful eyes, elegant noses, and fuller lips - all within ideal proportions. Once the needle breaks the facial skin envelope, it can encounter vital structures; therefore, it is necessary for the esthetic physician to have an in-depth understanding of facial injection anatomy to avoid disastrous complications such as blindness due to accidental filler or fat vascular occlusion. ${ }^{1-3}$ 
An abundance of conjectures exists in many empirical and narrative articles regarding physicians' lack of anatomical proficiency. ${ }^{4-8}$ Both anatomists and clinicians agree that precise understanding of facial anatomy and individual variations is crucial ${ }^{9}$ to assure safe and efficient procedural outcomes from injection of facial fillers.

Anatomy instructions are under-taught within appropriate contexts, such as clinical procedures. It is easier to transfer anatomical knowledge to solve a clinical problem by retrieving a concept that was learned in context. Anatomy teaching is primarily delivered by nonclinical teachers, who may not possess an apposite clinical perspective. ${ }^{10}$ Globally, in many medical schools, anatomy teaching, amidst didactic lectures and cadaveric dissection, has been reduced. ${ }^{11,12}$ Research has revealed that integrated curricula (such as problem solving, system-based learning, and computer-assisted learning) are replacing competent teachers and facilitators in anatomy laboratories to assist students in erudition, which deprives them of interactions with knowledgeable mentors. ${ }^{13}$ Study behavior and knowledge retention appear to be partially dependent on the examination pattern. Prior awareness of the format of assessment (eg, multiple choice questions [MCQs]) has a strong influence on the way anatomical knowledge is compartmentalized and retained. ${ }^{6,14}$ Iteration and reiteration in the context have a strong impact on the learning and retention of anatomical knowledge. However, limited time allocation for anatomy teaching in medical schools poses a challenge. ${ }^{15-17}$

Due to a growing practitioner demand and perceived need, many pharmaceutical and device companies have instituted training programs to refresh anatomical knowledge of their physician clientele to promote safer injection techniques. These symposia are based on the belief that simple exposure to basic anatomy would intuitively lead to the learning of safer injection techniques. Moreover, following Professor Bruce Keogh's report on "Review of the Regulation of Cosmetic Interventions," it was recommended that the Health Education England's mandate should include the development of appropriate accredited qualifications for providers of nonsurgical facial esthetic interventions. ${ }^{18}$ This has led to a surge in the number of training institutes providing such qualifications in UK. However, there is little evidence of a standardized instructional teaching design, where complex knowledge of facial anatomy and nonsurgical procedural skills is taught, following the appropriate teaching and learning andragogy.

Most of the small group, clinical skills teaching, follows the well-known Peyton's ${ }^{19}$ four-step approach (demonstration, deconstruction, comprehension, and execution), based on
Bloom's taxonomy, which was initially designed to support $1: 1$ teaching.

Bloom's ${ }^{20}$ taxonomy of learning objectives has been the foundation for deconstructing and reasoning about the aim of educational interventions, in cognitive and affective domains only. ${ }^{21}$ Subsequent work by many authors bridged the gap, by adding the psychomotor domain and covering the learning and acquisition of skills. ${ }^{22-24}$

Subsequently, Dawson ${ }^{25}$ revised and refined Bloom's taxonomy into four definite steps, namely observation, refinement, consolidation, and mastery. This has created an opportunity for assessment in the latter three steps to confirm the knowledge gain and procedural skill acquisition. On the review of the present medical literature, to the authors' best knowledge, no empirical, evidence-based educational model exists for teaching complex facial anatomy and related procedural skills, employing all the three learning domains.

The present study was proposed to design and evaluate a new educational intervention for large group teaching of applied facial anatomy and procedural skills based on the revised Bloom's taxonomy. We hypothesized that such a teaching model could be applied to teaching and assessing the complex facial anatomy and procedural skills in a large group setting.

\section{Materials and methods Development of the teaching model}

The first author (NK) developed a six-step approach ADDAPT (Assess \& Aware, Demonstrate, Decode, Act \& Accomplish, Perform, Teach \& Test) under the supervision of co-author (ER) for the teaching of applied facial anatomy and related procedural skills (ie, injection of botulinum toxin type A and dermal fillers) to esthetic physicians (Figure 1).

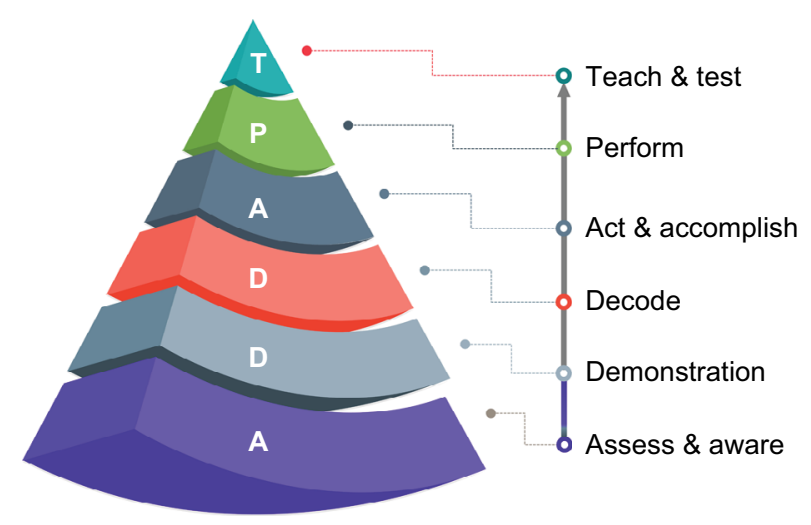

Figure I ADDAPT teaching steps.

Abbreviation: ADDAPT, Assess \& Aware, Demonstrate, Decode, Act \& Accomplish, Perform, Teach \& Test. 


\section{Steps of delivery}

Step I: assess \& aware

The MCQs and objective structured practical examination (OSPE) are conducted at the beginning of the course to assess the baseline knowledge of the trainees. The lead tutor (LT) introduces the topic by delivering a 10-minute snap presentation to make the learners aware of the knowledge, skills, and their significance as part of the conceptualization.

\section{Step 2: demonstrate}

The LT demonstrates the relevant surface marking, injection technique, and corresponding anatomical structures. The individual table demonstrators then repeat the procedure without description to create a broad visual perception. This visualization is a critical step in the psychomotor domain since the learners often use this to evaluate their skills.

\section{Step 3: decode}

The LT performs the procedure with the narration of the individual steps (often referred to as verbalization). The verbalization is a crucial stage of learning for acquiring new skills, as the auditory stimulus reinforces the visual memory. The table demonstrator repeats the step while the learners have a chance to ask any questions to clarify their understanding.

\section{Step 4: act \& accomplish}

The next step is for the trainees to internalize the one subset of skills in a cycle. Trainee 1 completes the surface marking, trainee 2 marks the injection points, trainee 3 explains the corresponding anatomy, trainee 4 performs the injection procedure, and trainee 5 explains the clinical relevance, under the guidance of the table demonstrator, and aided by the peer narration. This cycle is repeated until all the learners have completed all the subsets of skills. Iteration and reiteration help them to improve their understanding, thereby reinforcing the internalization of the taught knowledge and skills.

\section{Step 5: perform}

Trainees simulate the injection procedure independently on the cadaveric face by completing the spotting/flagging, surface marking under the observation of the table demonstrator. The table demonstrator gives immediate feedback on their performance.

\section{Step 6: teach \& test}

The trainees do peer teaching on one skill set assigned by the table demonstrator, followed by feedback from the table demonstrator and peers. As a final step, all the trainees take the formative assessment MCQs and OSPE to evaluate the knowledge and skills gained from the session.

\section{Study design}

In this quasi-experimental design, the authors examined the effectiveness and practicality of the ADDAPT model, a new approach to teaching applied facial anatomy and procedural skills to esthetic physicians in a large group setting. The study was conducted with two cohorts $(n=124)$ of esthetic physicians who underwent a 2-day applied facial anatomy course at the Academia, Singapore. The study was approved by the Faculty Research Ethics Panel of the Faculty of Medical Science, Anglia Ruskin University, Chelmsford, UK.

\section{Participants}

Participation in the workshop was invitation-based to esthetic physicians, dermatologists, and plastic surgeons. The mean experience of practicing nonsurgical esthetic procedures was 9.18 years with a mix of male (38.7\%) and female $(61.3 \%)$ participants.

\section{Course structure}

A 2-day course was designed to ensure the in-depth learning of applied facial anatomy relevant to nonsurgical injection therapy using fresh frozen cadavers. Emphasis was placed on safer injection techniques linked to vital anatomical structures through active trainee participation as described in previous publications. ${ }^{1,26}$

\section{Course delivery}

The course was delivered over two cohorts ( $\mathrm{n}=124)$, utilizing a plastic surgeon with over 20 years of clinical and teaching experience as the LT. Each table group was organized into smaller units of 5 , wherein esthetic practitioners with over 10 years of clinical experience acted as table demonstrators to guide and facilitate active participation and to keep the group task focused (Figure 2).

\section{Assessment methods}

A formal 20-minute examination was administered before and after the course (pre-/post-course). The test comprised 25 MCQs focused on factual and case-based applied facial anatomy knowledge. MCQs have been proven reliable in testing both recall and recognition. ${ }^{27}$ In addition to recall and recognition, the test format has a unique ability to assess the participants' conceptual understanding, rather than merely the regurgitation of facts. 
An OSPE for procedural skills was also instituted pre and post-course, as it involves visual, logical, linguistic, kinesthetic, and interpersonal intelligence. ${ }^{28}$ Blueprinting of the OSPE was done according to the previously published global consensus on the "core syllabus" for applied facial anatomy teaching to esthetic physicians. ${ }^{26}$ Thirty-one stations were constructed, where participants spent 1 minute at each station.

\section{Independent expert rating}

Two independent experts, blinded to the study, evaluated the entire session on an 11-point Likert scale $(0=$ strongly

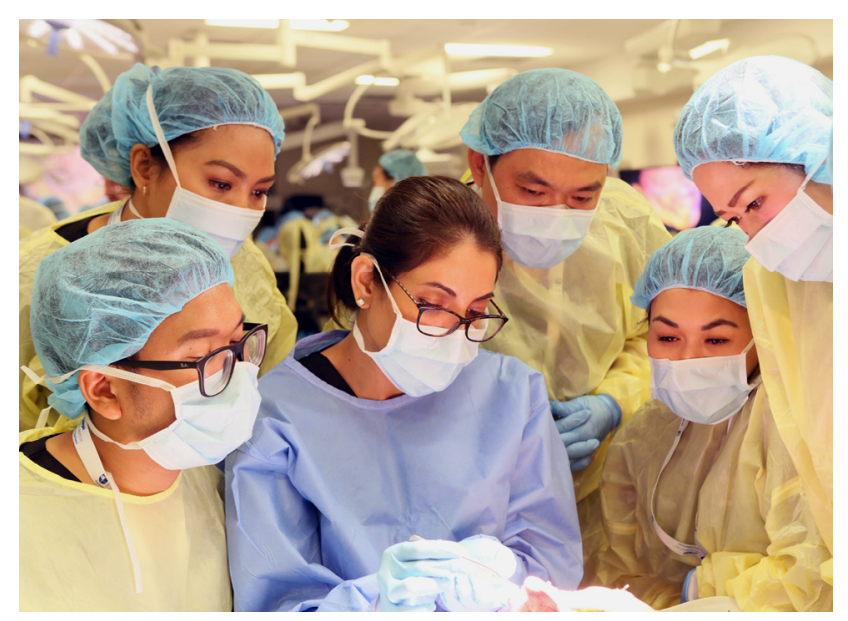

Figure 2 Students engagement in the small group where the table demonstrator is explaining the steps of the procedure. disagree, $10=$ strongly agree) and gave their feedback on both didactic and procedural aspects of the teaching (Table 1).

\section{Table demonstrators' rating}

Table demonstrators $(n=11)$ were also asked to complete an 11-point Likert scale rating $(0=$ strongly disagree, $10=$ strongly agree) on theoretical and practical aspects of the session, especially on the content, flow, timing, group interaction, and peer feedback (Table 1).

\section{Participant feedback}

Participants were asked to give their feedback after the session on an 11-point Likert scale $(0=$ strongly disagree, $10=$ strongly agree). The questionnaire was based on the knowledge and skills gained in the cognitive, affective, and psychomotor domains. Participants also gave feedback on teaching processes (ADDAPT), such as skill segmentation, reiterations, demonstrators, peer feedback, and overall skills gained from the session which could be applied in clinical practice. They were also asked to give additional comments regarding the session in general or any suggestions for future improvement.

\section{Statistical analyses}

The descriptive statistics were expressed in frequency, mean, and SD. A paired-sample $t$-test was performed to compare

Table I ADDAPT rating scale

\begin{tabular}{|c|c|c|c|}
\hline Steps & Expert rater & Table demonstrator & $\begin{array}{l}\text { Rating } \\
(0=\text { strongly disagree, } \\
\text { I } 0=\text { strongly agree })\end{array}$ \\
\hline A & $\begin{array}{l}\text { Content and pace are adequate to capture the } \\
\text { attention of the participants }\end{array}$ & $\begin{array}{l}\text { Content and pace are adequate to capture } \\
\text { the attention of the participants }\end{array}$ & \\
\hline D & $\begin{array}{l}\text { - The LT is confident in demonstrating anatomy and } \\
\text { procedural skills } \\
\text { - The individual group demonstrators mirrored the } \\
\text { skills accurately and competently }\end{array}$ & $\begin{array}{l}\text { The LT is confident in demonstrating anatomy } \\
\text { and procedural skills }\end{array}$ & \\
\hline D & - The procedural narration is clear, concise, and fluid & $\begin{array}{l}\text { The procedural narration is clear, concise, } \\
\text { and fluid }\end{array}$ & \\
\hline $\mathbf{A}$ & $\begin{array}{l}\text { - The participants repeated the steps without } \\
\text { interruption } \\
\text { - The demonstrators can control the group }\end{array}$ & $\begin{array}{l}\text { The participants repeated the steps without } \\
\text { interruption }\end{array}$ & \\
\hline $\mathbf{P}$ & $\begin{array}{l}\text { Feedback provided to the participants is adequate and } \\
\text { clear }\end{array}$ & $\begin{array}{l}\text { Feedback provided to the participants is } \\
\text { adequate and clear }\end{array}$ & \\
\hline $\mathbf{T}$ & $\begin{array}{l}\text { - Trainees were thoroughly engaged in peer teaching } \\
\text { - Questions were written in the appropriate format } \\
\text { - Time allocated to complete the examination was } \\
\text { adequate }\end{array}$ & $\begin{array}{l}\text { - Trainees were thoroughly engaged in peer } \\
\text { teaching } \\
\text { - Questions were written in the appropriate } \\
\text { format } \\
\text { - Time allocated to complete the } \\
\text { examination was adequate }\end{array}$ & \\
\hline
\end{tabular}

Abbreviations: ADDAPT, Assess \& Aware, Demonstrate, Decode, Act \& Accomplish, Perform, Teach \& Test; LT, lead tutor. 
the pre-/posttest scores of the MCQs and OSPE to ascertain the statistical significance. All $P$-values were two tailed, and statistical significance was set at $P \leq 0.05$. The agreement among the independent expert raters was measured by computing the two-way mixed intraclass correlation coefficient (ICC) for consistency. An ICC value of $>0.7$ is considered as satisfactory. ${ }^{29}$ Although Cohen's $\kappa$ is a more stringent measure of the inter-rater agreement, it was not employed because of the presence of 5 or more rating categories. The same statistical principle was also applied to measure the agreement between the table demonstrators.

IBM SPSS Statistics for Windows, Version 24.0 (IBM Corporation, Armonk, NY, USA) was used to analyze quantitative data.

\section{Results}

Pre-/post-course evaluation mean scores for MCQs were 17.32 (SD \pm 3.36$)$ and 22.61 (SD \pm 1.77$)$ and OSPE scores were 24.53 ( $\mathrm{SD} \pm 4.63$ ) and 43.57 ( $\mathrm{SD} \pm 5.35)$, respectively $(P<0.001$; Tables 2 and 3; Figures 3 and 4). Delegates from all the specialties showed improvement in their applied anatomy knowledge and related procedural skills based on the comparison of pre- and posttest scores $(P<0.001)$.

Two independent expert raters, blinded to the study, demonstrated less variance and higher reliability, where ICC was 0.91 (95\% CI: 0.62-0.98). A similar trend was observed among the table demonstrators, where ICC was $0.90(95 \%$ CI: 0.78-0.97), considered as excellent (Tables 4 and 5).

Table 2 Paired-samples statistics

\begin{tabular}{|l|l|l|l|l|l|}
\hline \multicolumn{2}{|l|}{ Mean } & N & SD & $\begin{array}{l}\text { Standard } \\
\text { error of the } \\
\text { mean }\end{array}$ \\
\hline \multirow{2}{*}{ Pair I } & MCQ_pre & 17.3226 & 124 & 3.36058 & 0.30179 \\
\cline { 2 - 6 } & MCQ_post & 22.7500 & 124 & 1.70425 & 0.15305 \\
\hline \multirow{2}{*}{ Pair 2 } & OSPE_pre & 24.5323 & 124 & 4.63538 & 0.41627 \\
\cline { 2 - 6 } & OSPE_post & 43.5726 & 124 & 5.35894 & 0.48125 \\
\hline
\end{tabular}

Abbreviations: MCQ, multiple choice question; OSPE, objective structured practical examination.
Evaluation rating with better inter-rater agreement reflects credibility and strength of good educational intervention. ${ }^{30}$

Feedback confirmed the acceptance and practicability of the ADDAPT model by the participants, as they gained sufficient knowledge and the necessary skills during the course applicable to their clinical practice. Additional comments included "sessions were intellectually stimulating", "segmentation of the procedural skills was clear", and "repeated observation within the group" were beneficial. Attendees noted that the peer-assisted learning, as well as the feedback provided by the table demonstrators and peers, was very constructive and helpful (Figure 5).

\section{Discussion}

Facial rejuvenation with the use of soft tissue fillers is a popular and growing nonsurgical esthetic procedure globally. Due to rapid growth which now runs in millions of syringes in a year, rare but severe vascular complications including iatrogenic blindness are seen by many practicing physicians. A recent review article reported 98 cases of blindness due to soft tissue filler injections and highlighted the importance of comprehensive understanding of facial anatomy knowledge. ${ }^{3,26}$ Currently, nonsurgical facial esthetic procedures are primarily taught outside of the formal medical school curriculum; trainees are mostly exposed to a "show and tell" type of course in various symposia and congresses. Such an approach is unlikely to provide enough opportunity to learners for the development of their affective and psychomotor skills in a structured way. Hence, it is essential to develop and validate a postgraduate nonsurgical facial esthetic curriculum to have a safe esthetic practice. As the target audience is the mature, postgraduate, clinical students, more careful attention should be given to address the format of instruction. Adult learners with a different approach to learning are interested in knowing the immediate gain from the process. This attitude presents with questions such as "what is in it for me?" or "can this learning be used in clinical practice?" Therefore, the medical educator's goal should be continuously trying to move his/her trainee to a higher level of human learning

Table 3 Paired-samples test

\begin{tabular}{|c|c|c|c|c|c|c|c|c|}
\hline \multirow{3}{*}{\multicolumn{2}{|c|}{ Mean }} & \multirow[t]{3}{*}{ SD } & \multicolumn{3}{|c|}{ Paired differences } & \multirow[t]{3}{*}{$\mathbf{t}$} & \multirow[t]{3}{*}{ df } & \multirow{3}{*}{$\begin{array}{l}\text { Significance } \\
\text { (two-tailed) }\end{array}$} \\
\hline & & & \multirow{2}{*}{$\begin{array}{l}\text { Standard error } \\
\text { of the mean }\end{array}$} & \multicolumn{2}{|c|}{ 95\% $\mathrm{Cl}$ of the difference } & & & \\
\hline & & & & Lower & Upper & & & \\
\hline Pair I:MCQ_post-MCQ_pre & 5.42742 & $3.0555 I$ & 0.27439 & 4.88428 & 5.97056 & 19.780 & 123 & 0.000 \\
\hline Pair 2: OSPE_post-OSPE_pre & 19.04032 & 6.39664 & 0.57444 & 17.90326 & 20.17738 & 33.146 & 123 & 0.000 \\
\hline
\end{tabular}

Abbreviations: MCQ, multiple choice question; OSPE, objective structured practical examination. 


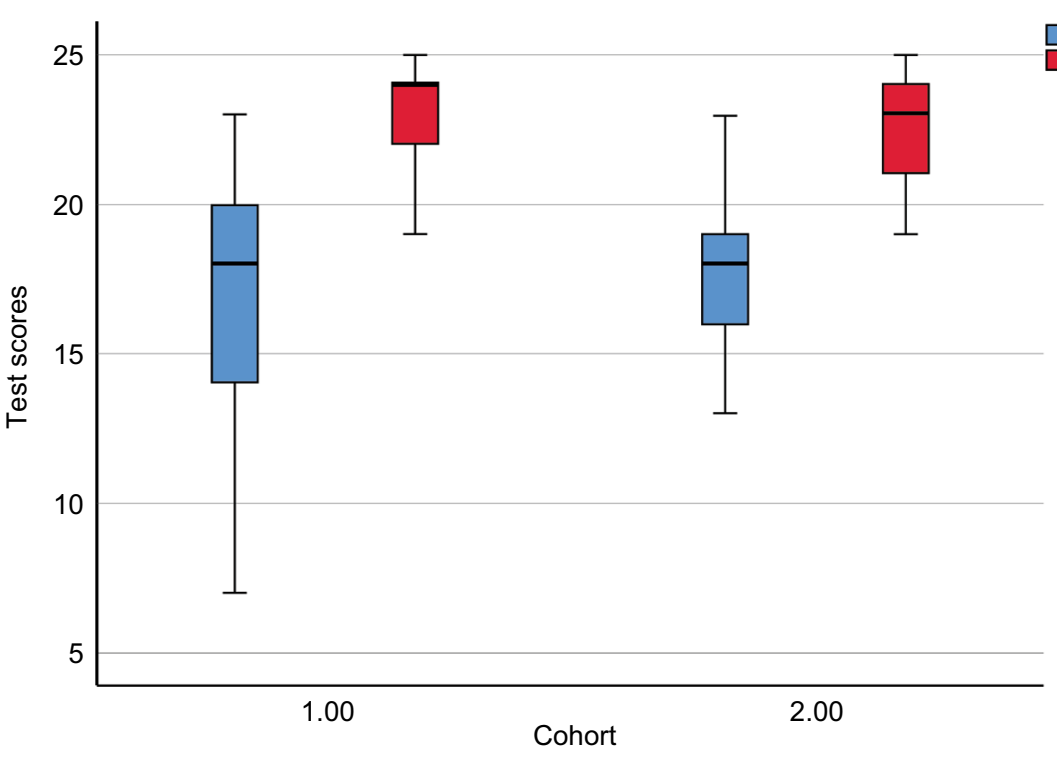

Figure $3 \mathrm{MCQ}$ pre- and posttest score.

Abbreviation: MCQ, multiple choice question.

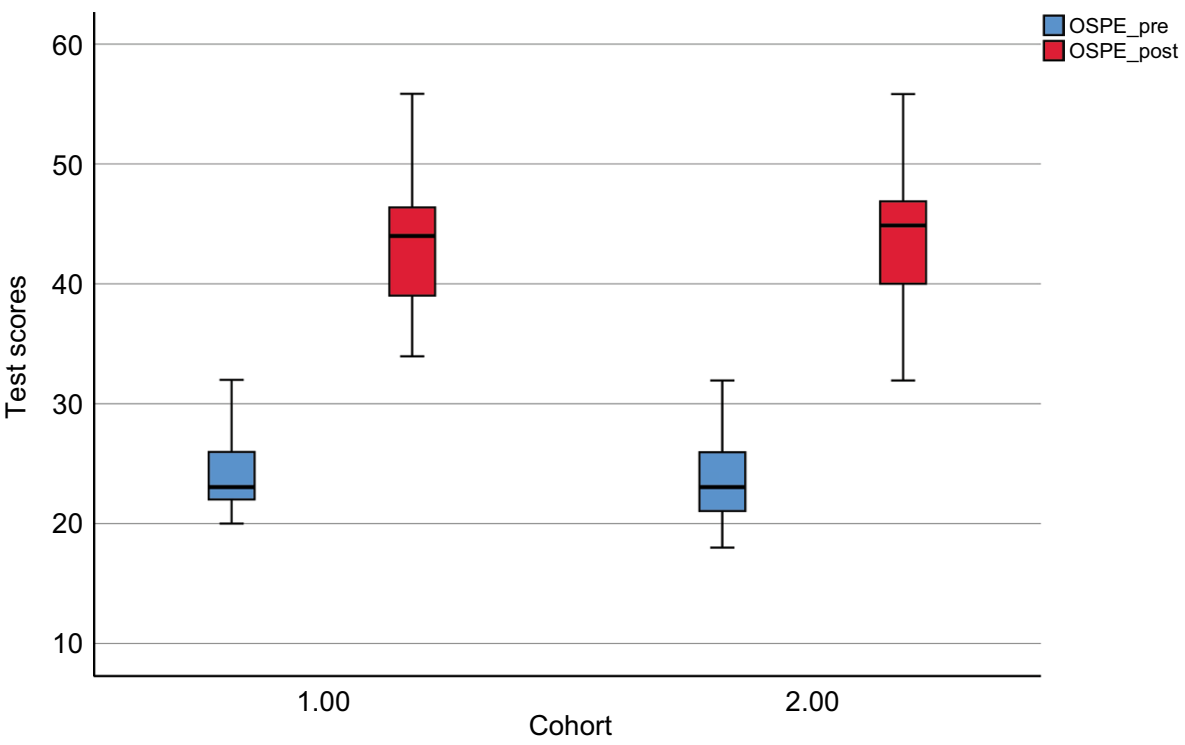

Figure 4 OSPE pre- and posttest score.

Abbreviation: OSPE, objective structured practical examination.

Table 4 Reliability statistics among independent expert raters

\begin{tabular}{|c|c|c|c|c|c|c|c|}
\hline & \multirow{2}{*}{$\begin{array}{l}\text { Intraclass } \\
\text { correlation }^{a}\end{array}$} & \multicolumn{2}{|l|}{$95 \% \mathrm{Cl}$} & \multirow[t]{2}{*}{ Value } & \multicolumn{3}{|c|}{ F-test with true value 0} \\
\hline & & Lower bound & Upper bound & & df I & df2 & Significance \\
\hline Single measures & $0.826^{b}$ & 0.447 & 0.954 & 10.524 & 9 & 9 & 0.001 \\
\hline Average measures & $0.905^{c}$ & 0.617 & 0.976 & 10.524 & 9 & 9 & 0.001 \\
\hline
\end{tabular}

Notes: Two-way mixed-effects model where people effects are random and measures effects are fixed. ${ }^{\mathrm{a}}$ Type $\mathrm{C}$ ICCs using a consistency definition. The between-measure variance is excluded from the denominator variance. ${ }^{\mathrm{b}}$ The estimator is the same, whether the interaction effect is present or not. ${ }^{\mathrm{C}}$ This estimate is computed assuming the interaction effect is absent, because it is not estimable otherwise.

Abbreviation: ICC, intraclass correlation coefficient. 
Table 5 Reliability statistics among table demonstrators

\begin{tabular}{|c|c|c|c|c|c|c|c|}
\hline \multicolumn{8}{|l|}{ ICC } \\
\hline & \multirow{2}{*}{$\begin{array}{l}\text { Intraclass } \\
\text { correlation }^{\mathbf{a}}\end{array}$} & \multicolumn{2}{|l|}{$95 \% \mathrm{Cl}$} & \multirow[t]{2}{*}{ Value } & \multicolumn{3}{|c|}{ F-test with true value 0} \\
\hline & & Lower bound & Upper bound & & dfI & df2 & Significance \\
\hline Single measures & $0.452^{b}$ & 0.239 & 0.752 & 10.073 & 9 & 90 & 0.000 \\
\hline Average measures & $0.90 \mathrm{I}^{\mathrm{c}}$ & 0.776 & 0.971 & 10.073 & 9 & 90 & 0.000 \\
\hline
\end{tabular}

Notes: Two-way mixed-effects model where people effects are random and measures effects are fixed. ${ }^{\mathrm{a}}$ Type $\mathrm{C}$ ICCs using a consistency definition. The between-measure variance is excluded from the denominator variance. ${ }^{\mathrm{b}}$ The estimator is the same, whether the interaction effect is present or not. ${ }^{\mathrm{c}}$ This estimate is computed assuming the interaction effect is absent, because it is not estimable otherwise.

Abbreviation: ICC, intraclass correlation coefficient.

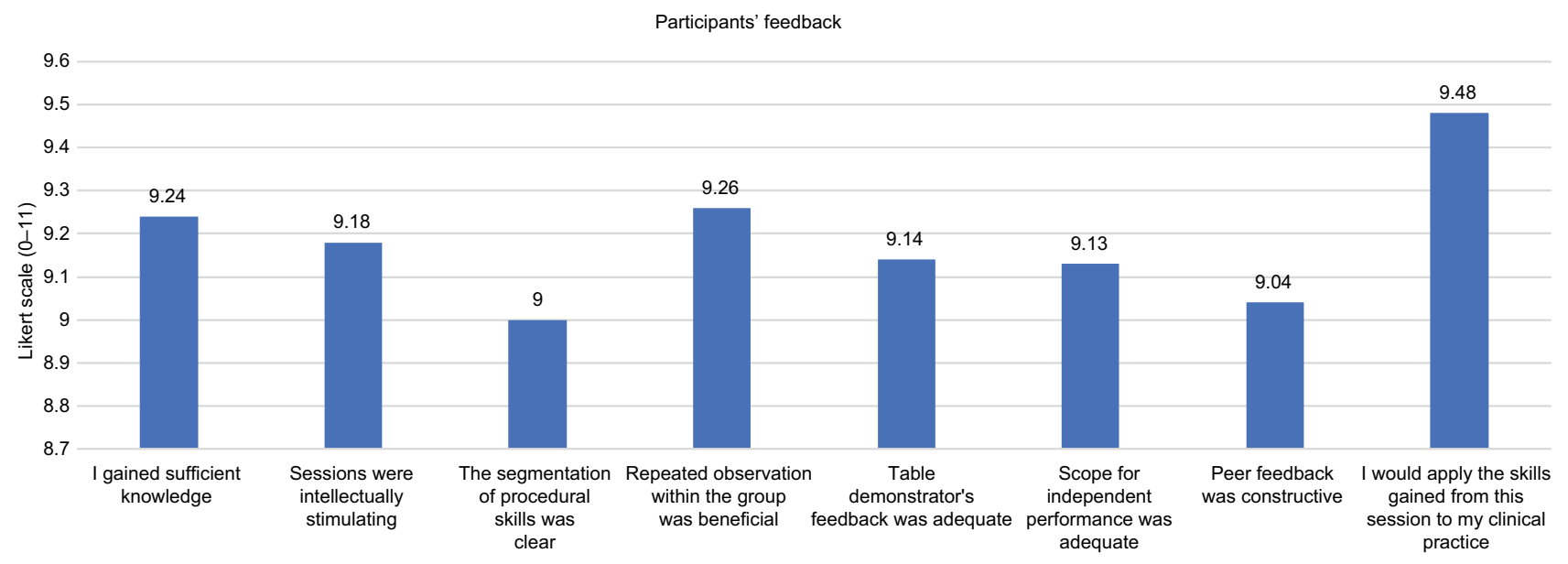

Figure 5 Participants' qualitative feedback.

by touching cognitive (knowledge or head), affective (heart or feeling), and psychomotor (kinesthetic or hand) domains. At the beginning of a learning process for the psychomotor task, trainees should be provided with an intellectual stimulus by using a sententious approach, covering the cognitive and affective domain of learning.

Health care practitioners require the development of psychomotor skills; therefore, it is one of the key learning outcomes in all the medical education curricula. Unfortunately, medical schools emphasize developing the learning framework around the cognitive and affective domains and leave the progress of psychomotor skills to a clinical clerkship, where trainees are provided with controlled clinical practice opportunities. The success of such an approach is reliant on the competency of clinical supervisors. Institutions are relying on qualified clinicians in the workplace to educate and develop the psychomotor skills of trainees during these supervised sessions. However, these clinicians often have inadequate knowledge of instructional theory. ${ }^{31}$ Thus, ADDAPT successfully implements all the three domains of learning, ie, cognitive, affective and the psychomotor by providing a platform that is clear, time specific, and outcome- based where a sound knowledge of anatomy is gained, then applied and tested before any complex facial esthetic procedures are taught.

To the best of our knowledge, the current study is the first to present and appraise not only the methodological approach to anatomy-based procedural skill teaching in a large group setting, but also to facilitate working in a group assisted by peer-assisted learning, involving all the domains of human learning. ADDAPT's six steps provide a well-organized erudition pathway as they give structure to the facial anatomy lesson plan that fits several learning styles. The authors described a practical teaching approach with clearly defined steps focusing on different stages of learning a complex task such as conceptualization, visualization, verbalization, and actualization. Since trainees may have a wide range of learning styles, they learn most efficiently from a combination of activities that kindles the visual, auditory, verbal (read-write), and kinesthetic sensory modalities. ${ }^{32}$

Pre- and post-course assessment results during the anatomy workshop prove the practicability of the ADDAPT model for large group teaching. The trainees, as well as the table demonstrators, acknowledged and rated the ADDAPT 
model as easy to implement, resulting in a good flow of teaching and success in attracting the trainees' attention. With the ADDAPT model, trainees get sufficient opportunity to build their understanding on the taught knowledge and skills during the first three steps (assess $\&$ aware, demonstrate, decode), while the last three steps (act \& accomplish, perform, and teach $\&$ test) focus on the internalization by performing the learnt skills. Step 4 (act \& accomplish) and step 5 (perform) are the anchors of this model and superior to Peyton's ${ }^{19}$ third and fourth step (comprehension and performance) as evident by the participant's feedback (Figure 5), where the peers and table demonstrators facilitate learning in a safe environment. Feedback is proven to be highly effective in the learning process, ${ }^{33}$ a gift that benefits in making the trainees aware of their strength and areas to focus. Although the ADDAPT model is a simple approach, it propounds a strategy for explicit instruction, by engaging all participants to focus on optimizing the overall learning experience and attaining skill mastery.

The ADDAPT model is a three-dimensional teaching and assessment framework, where complex nonsurgical facial esthetic interventions and elaborate facial anatomy were taught to attain mastery of the necessary skills. This unified teaching model has facilitated an interdependent learning network aided by peer-assisted learning, which has proven to be the soul of modern medical education. Combining such tools not only enforces theoretical knowledge and refinement of procedural skills by repetition but also helps in minimizing potentially serious complications. ${ }^{1}$ Thus, the ADDAPT model has proven to be advantageous in taking students on a journey involving all three domains of human learning.

\section{Limitations}

This research has several limitations. First, we conducted the study without any control group, in two cohorts and at a single center, as it limits the external validity. We suggest replicating the present study at different centers with multiple cohorts to evaluate its practicality and effectiveness. Second, conducting an OSPE for a large group and maintaining 1:5 (table demonstrator:trainee) ratio require extensive resource planning regarding infrastructure and time, which can be challenging in many situations. Lastly, it is difficult to estimate the impact of this educational intervention on clinical practice, such as safer injection techniques. Patient-related outcomes usually are not a quixotic proxy to establish the effectiveness of the educational intervention. Regardless of this, most educational interventions are based on the rational assumption that knowledge and skill attainment eventually lead to improved patient care.

\section{Conclusion}

The current study has proposed and evaluated a new and innovative teaching model ADDAPT - a six-step approach - which is useful in teaching applied facial anatomy and procedural skills to esthetic physicians in a large group setting. Both participants and tutors accepted the ADDAPT model very well. This alternative to conventional instructional design may be workable and transferable to other areas of psychomotor skill training in medical education.

\section{Acknowledgment}

The authors want to express gratitude to Dr Greg Goodman, Associate Professor, Monash University, Melbourne, VIC, Australia, and Dr Arthur Swift, Clinical Lecturer, McGill University, Montreal, QC, Canada, for comments that significantly improved the manuscript.

\section{Disclosure}

The authors report no conflicts of interest in this work.

\section{References}

1. Kumar N, Rahman E. Effectiveness of teaching facial anatomy through cadaver dissection on aesthetic physicians' knowledge. Adv Med Educ Pract. 2017;8:475-480.

2. Signorini M, Liew S, Sundaram H, et al. Global Aesthetics Consensus. Plast Reconstr Surg. 2016;137(6):961e-971e.

3. Beleznay K, Carruthers JDA, Humphrey S, Jones D. Avoiding and Treating Blindness From Fillers: A Review of the World Literature. Dermatologic Surg. 2015;41(10):1097-1117.

4. Cottam WW. Adequacy of medical school gross anatomy education as perceived by certain postgraduate residency programs and anatomy course directors. Clin Anat. 1999;12(1):55-65.

5. Waterston SW, Stewart IJ. Survey of clinicians' attitudes to the anatomical teaching and knowledge of medical students. Clin Anat. 2005;18(5):380-384.

6. Older J. Anatomy: a must for teaching the next generation. Surgeon. 2004;2(2):79-90.

7. Estai M, Bunt S. Best teaching practices in anatomy education: A critical review. Ann Anat. 2016;208:151-157.

8. Marks SC, Cahill DR. Teaching and learning anatomy in medicine. Clin Anat. 1988;1(1):3-5.

9. Raftery AT. Anatomy teaching in the UK. Surgery. 2007;25(1):1-2.

10. Bergman EM, van der Vleuten CP, Scherpbier AJ. Why don't they know enough about anatomy? A narrative review. Med Teach. 2011;33(5): 403-409.

11. Craig S, Tait N, Boers D, Mcandrew D. Review of anatomy education in Australian and New Zealand medical schools. ANZ J Surg. 2010;80(4):212-216.

12. Bouwer HE, Valter K, Webb AL. Current integration of dissection in medical education in Australia and New Zealand: Challenges and successes. Anat Sci Educ. 2016;9(2):161-170.

13. Cahill DR, Leonard RJ, Marks SC. A comment on recent teaching of human anatomy in the United States. Surg Radiol Anat. 2000;22(2):69-71. 
14. Turney BW. Anatomy in a modern medical curriculum. Ann R Coll Surg Engl. 2007;89(2):104-107.

15. Manyama M, Stafford R, Mazyala E, et al. Improving gross anatomy learning using reciprocal peer teaching. BMC Med Educ. 2016; 16(1):95.

16. Dyer GS, Thorndike ME. Quidne mortui vivos docent? The evolving purpose of human dissection in medical education. Acad Med. 2000;75(10):969-979.

17. Aziz MA, McKenzie JC, Wilson JS, Cowie RJ, Ayeni SA, Dunn BK. The human cadaver in the age of biomedical informatics. Anat Rec. 2002;269(1):20-32.

18. Keogh SB. Review of the Regulation of Cosmetic Interventions. United Kingdom; 2013. Available from: https://www.gov.uk/government/ uploads/system/uploads/attachment_data/file/192028/Review_of_the Regulation_of_Cosmetic_Interventions.pdf. Accessed November 26, 2018.

19. Peyton JWR, editor. Teaching \& Learning in Medical Practice. Heronsgate 1st ed. Rickmansworth (UK): Manticore Europe Ltd.; 1998

20. Bloom BS, editor. Taxonomy of Educational Objectives. Handbook 1: Cognitive Domain. 1st ed. New York (NY): Addison-Wesley Longman Ltd.; 1956.

21. Krathwohl DR, Bloom BS, Masia BB. Taxonomy of Educational Objectives, Handbook II: Affective Domain (The Classification of Educational Goals). New York (NY): David McKay; 1956.

22. Dave RH. Psychomotor levels. In: Armstrong RJ, editor. Developing and Writing Behavioral Objectives. Tucson (AZ): Educational Innovators Press; 1970.
23. Cooper WF, Harrow AJ. A Taxonomy of the Psychomotor Domain: A Guide for Developing Behavioral Objectives. Am Educ Res J. 1973;10(4):325.

24. Simpson E. The classification of educational objectives in the psychomotor domain. Education. 1972;3(3):43-56.

25. Dawson WR. Extensions to Bloom's Taxonomy of Educational Objectives. Sydney: Putney Publishing; 1998.

26. Kumar N, Swift A, Rahman E. Development of "Core Syllabus" for Facial Anatomy Teaching to Aesthetic Physicians. Plast Reconstr Surg Glob Open. 2018;6(3):e1687.

27. Arzi HJ, Ben-Zvi R, Ganiel U. Forgetting versus savings: The many facets of long-term retention. Sci Educ. 1986;70(2):171-188.

28. Gardner H. Intelligence Refrained: Multiple Intelligences for the 21st Century. New York (NY): Basic Books; 1999.

29. Bland JM, Altman DG. Cronbach's alpha. BMJ. 1997;314(7080):572.

30. Graham M, Milanowski A, Miller J. Measuring and promoting interrater agreement of teacher and principal performance ratings. Cent Educ Compens Reform. 2012;33. Available from: http://files.eric.ed.gov/ fulltext/ED532068.pdf. Accessed November 27, 2018.

31. Thoirs K, Coffee J. Developing the clinical psychomotor skills of musculoskeletal sonography using a multimedia DVD: A pilot study. Australas J Educ Technol. 2012;28(4):703-718.

32. Kharb P, Samanta PP, Jindal M, Singh V. The learning styles and the preferred teaching-learning strategies of first year medical students. J Clin Diagn Res. 2013;7(6):1089-1092.

33. Barry Issenberg S, McGaghie WC, Petrusa ER, Lee Gordon D, Scalese RJ. Features and uses of high-fidelity medical simulations that lead to effective learning: a BEME systematic review. Med Teach 2005. 2005;27:28.
Advances in Medical Education and Practice

\section{Publish your work in this journal}

Advances in Medical Education and Practice is an international, peerreviewed, open access journal that aims to present and publish research on Medical Education covering medical, dental, nursing and allied health care professional education. The journal covers undergraduate education, postgraduate training and continuing medical education

\section{Dovepress}

including emerging trends and innovative models linking education, research, and health care services. The manuscript management system is completely online and includes a very quick and fair peer-review system. Visit http://www.dovepress.com/testimonials.php to read real quotes from published authors. 